\title{
Anthropogenic and natural contributions to tropospheric sulfate: A global model analysis
}

\section{Citation}

Chin, Mian, and Daniel J. Jacob. 1996. "Anthropogenic and Natural Contributions to Tropospheric Sulfate: A Global Model Analysis.” Journal of Geophysical Research 101 (D13): 18691. doi:10.1029/96jd01222.

\section{Published Version}

doi:10.1029/96JD01222

\section{Permanent link}

http://nrs.harvard.edu/urn-3:HUL.InstRepos:14061857

\section{Terms of Use}

This article was downloaded from Harvard University's DASH repository, and is made available under the terms and conditions applicable to Other Posted Material, as set forth at http:// nrs.harvard.edu/urn-3:HUL.InstRepos:dash.current.terms-of-use\#LAA

\section{Share Your Story}

The Harvard community has made this article openly available.

Please share how this access benefits you. Submit a story.

\section{Accessibility}




\title{
Anthropogenic and natural contributions to tropospheric sulfate: A global model analysis
}

\author{
Mian Chin \\ Division of Applied Sciences, Harvard University, Cambridge, Massachusetts \\ Universities Space Research Association, NASA Goddard Space Flight Center, Greenbelt, Maryland \\ Daniel J. Jacob \\ Division of Applied Sciences and Department of Earth and Planetary Sciences, Harvard University, Cambridge \\ Massachusetts
}

\begin{abstract}
A global three-dimensional model is used to examine the export of anthropogenic sulfur from northern midlatitude continents and to assess the relative importance of anthropogenic and natural sources to sulfate levels in different regions of the troposphere. Model results indicate that about $40 \%$ of the anthropogenic sulfur emitted in the United States, Europe, or eastern Asia is exported out of the continental boundary layer of these regions; the rest is removed within the regions, primarily by dry deposition of $\mathrm{SO}_{2}$ and wet deposition of $\mathrm{SO}_{4}{ }^{2-}$. Export is relatively more efficient in summer than in winter. There is little nonlinearity between the magnitude of sulfur emissions in the northern midlatitude continents and the export of this sulfur to the global atmosphere. Anthropogenic influence on $\mathrm{SO}_{4}{ }^{2-}$ decreases rapidly with altitude because of efficient scavenging of $\mathrm{SO}_{2}$ and $\mathrm{SO}_{4}{ }^{2-}$ in deep convective updrafts. Thus it is found that anthropogenic influence accounts on average for less than $20 \%$ of $\mathrm{SO}_{4}{ }^{2-}$ anywhere in the upper troposphere. The main source of $\mathrm{SO}_{4}{ }^{2-}$ in the tropical upper troposphere in the model is from biogenic dimethylsulfide (DMS) pumped in deep convective events. Volcanic emissions account for $20-40 \%$ of $\mathrm{SO}_{4}{ }^{2-}$ in much of the middle troposphere and for up to $80 \%$ over the North Pacific; they also represent a major contributor to $\mathrm{SO}_{4}^{2-}$ in the upper troposphere at high latitudes. On a global scale, it is estimated that anthropogenic, biogenic, and volcanic emissions account for $70 \%, 23 \%$, and $7 \%$, respectively, of the global sulfur source, but that they account for $37 \%, 42 \%$, and $18 \%$, respectively, of the global column of atmospheric $\mathrm{SO}_{4}{ }^{2-}$. The disproportionality between source and column contribution reflects the rapid deposition of anthropogenic $\mathrm{SO}_{2}$ and $\mathrm{SO}_{4}{ }^{2-}$ at low altitudes. It thus appears that the anthropogenic contribution to the $\mathrm{SO}_{4}{ }^{2-}$ aerosol optical depth is much less than would be expected simply on the basis of emissions.
\end{abstract}

\section{Introduction}

Sulfate aerosol cools the Earth directly by scattering solar radiation and indirectly by providing condensation nuclei for cloud formation, increasing cloud albedo. Recent estimates suggest that the global radiative forcing from anthropogenic sulfur emissions may balance the radiative forcing from anthropogenic emissions of greenhouse gases [Intergovernmental Panel on Climate Change (IPCC), 1995]. However, because of the short lifetime of aerosols against deposition (days - weeks), the radiative forcing associated with aerosols varies strongly with region. A critical uncertainty in assessing the climatic effect of anthropogenic sulfur emissions is the spatial and temporal extent of the anthropogenic $\mathrm{SO}_{4}{ }^{2-}$ aerosol [IPCC, 1995]. We address this issue here by using a global threedimensional model with synoptic-scale resolution based on the Goddard Institute of Space Studies general circulation model (GISS GCM). A detailed description of the model, including evaluation with observations for $\mathrm{SO}_{4}{ }^{2-}$ and its precursors, is given by Chin et al. [this issue]. Here we apply the model to quantify the export (defined as the net outflow) of sulfur from northern midlat-

Copyright 1996 by the American Geophysical Union.

Paper number 96JD01222.

0148-0227/96/96JD-01222\$09.00 itude continents and to assess the relative contributions of anthropogenic and natural sources to $\mathrm{SO}_{4}{ }^{2-}$ levels in different regions of the atmosphere.

The principal anthropogenic sources of sulfur to the atmosphere are coal and oil combustion, oil refining, and smelting of ores; the main natural sources are oceanic phytoplankton and volcanoes. About $70 \%$ of the global emission of sulfur to the atmosphere is anthropogenic, and $70 \%$ of this anthropogenic source is concentrated in the United States, Europe, and eastern Asia [Spiro et al., 1992; Benkovitz et al., 1996]. Export of pollution from these continental regions is known to make significant seasonal contributions to $\mathrm{SO}_{4}{ }^{2-}$ levels over the North Atlantic (D. L. Savoie et at., Oceanic and anthropogenic contributions to non-sea-salt sulfate in the marine boundary layer over the North Atlantic Ocean, submilted to Journal of Geophysical Research, 1995), the Arctic [Barrie et al., 1989], and the North Pacific [Savoie and Prospero, 1989]. However, it appears also that only a small fraction of the sulfur emitted from polluted continents is actually exported, the remainder being deposited over the continent of origin [Galloway et al., 1984]. Understanding the processes determining the export of sulfur from polluted continents is evidently of great importance for assessing global human influence on $\mathrm{SO}_{4}{ }^{2-}$.

Several previous three-dimensional model studies have examined the anthropogenic contribution to $\mathrm{SO}_{4}{ }^{2-}$ aerosol on a global scale. Comparison of the global sulfur budgets in the different 
models is presented by Chin et al. [this issue]. Langner et al. [1992], using the coarse-resolution model MOGUNTIA, found that human activity had increased the $\mathrm{SO}_{4}{ }^{2-}$ burden by a factor of 2.8 in the northern hemisphere and a factor of 1.4 in the southern hemisphere since preindustrial time. Similar anthropogenic contributions to the $\mathrm{SO}_{4}{ }^{2-}$ burden were found by Penner et al. [1994] using a higher resolution, synoptic-scale model (GRANTOUR). Pham et al. [1996] found in their recent study using the IMAGES model that the increase of $\mathrm{SO}_{4}{ }^{2-}$ since preindustrial time was a factor of 4 in the northern hemisphere and a factor of 1.5 in the southern hemisphere. Our results, presented below, suggest that the global extent of human influence on $\mathrm{SO}_{4}{ }^{2-}$ is significantly less than inferred in these previous studies.

We begin the paper with a brief description of the model (section 2); further details are given by Chin et al. [this issue]. We then use the model in section 3 to analyze the export of anthropogenic sulfur from the northern midlatitude continents to the global atmosphere. The relative contributions of anthropogenic and natural sources to $\mathrm{SO}_{4}{ }^{2-}$ levels in different regions of the troposphere are examined in section 4 . Conclusions are in section 5.

\section{The Model}

The model solves the mass conservation equations for dimethylsulfide (DMS), $\mathrm{H}_{2} \mathrm{~S}, \mathrm{SO}_{2}, \mathrm{SO}_{4}{ }^{2-}$, and methanesulfonic acid (MSA), on a global three-dimensional grid with $4^{\circ}$ latitude $\times 5^{\circ}$ longitude resolution in the horizontal, nine layers in the vertical, and a time step of 4 hours. The grid follows that of the GISS GCM II [Hansen et al., 1983]. The vertical resolution (sigma coordinate) is such that the boundary layer below $2.6 \mathrm{~km}$ is resolved by three layers and the free troposphere above is resolved by four to five layers (the top model layer is in the stratosphere). Meteorological input to the model is provided by a 1-year archive of 4-hour average quantities from the GCM, including winds, convective mass fluxes, clouds, precipitation, and other variables.

Emission of $\mathrm{SO}_{2}$ from fossil fuel combustion and industrial activities $\left(65 \mathrm{Tg} \mathrm{S} \mathrm{yr}^{-1}\right)$ is specified from the Global Emissions Inventory Activity (GEIA) database for 1985 [Benkovitz et al., 1996]. Biomass burning represents a small additional source $(2.3$ $\mathrm{Tg} \mathrm{S} \mathrm{yr}^{-1}$ ). Biogenic sulfur emissions include DMS from the ocean (22 $\mathrm{Tg} \mathrm{S} \mathrm{yr}^{-1}$ ) and $\mathrm{H}_{2} \mathrm{~S}$ and DMS from terrestrial vegetation and soils $\left(0.9 \mathrm{Tg} \mathrm{S} \mathrm{yr}^{-1}\right)$. Volcanic emissions of $\mathrm{SO}_{2}$ include a noneruptive, continuously emitting component derived from a data base of volcanic activity for the early $1980 \mathrm{~s}\left(2.7 \mathrm{Tg} \mathrm{S} \mathrm{yr}^{-1}\right)$, and an eruptive component based on a chronology of volcanism for 1985 with daily resolution $\left(4.0 \mathrm{Tg} \mathrm{S} \mathrm{yr}^{-1}\right)$. Noneruptive emissions are emitted at the mouth of the volcano. Eruptive emissions for each individual volcano are distributed in time over the duration of the eruption, and vertically over the depth of the eruption plume, as described by Spiro et al. [1992] and Chin et al. [this issue]. Oxidation of carbonyl sulfide (OCS) is also included as a source of $\mathrm{SO}_{2}$ in the stratosphere $\left(0.03 \mathrm{Tg} \mathrm{S} \mathrm{yr}^{-1}\right)$ following Chin and Davis [1995].

The model accounts for gas-phase oxidation of DMS, $\mathrm{H}_{2} \mathrm{~S}$, and $\mathrm{SO}_{2}$ by $\mathrm{OH}$, using global three-dimensional fields of $\mathrm{OH}$ concentrations with 5-day resolution from Spivakovsky et al. [1990] and scaling the 24-hour average $\mathrm{OH}$ to the cosine of solar zenith angle. The model also accounts for nighttime oxidation of DMS by $\mathrm{NO}_{3}$, and for an additional DMS oxidant as necessary to yield a DMS lifetime consistent with observed DMS concentrations in the marine boundary layer (see Chin et al. [this issue] for further discussion). Aqueous-phase oxidation of $\mathrm{SO}_{2}$ by $\mathrm{H}_{2} \mathrm{O}_{2}$ in clouds is simulated as a rapid process limited solely by the availability of
$\mathrm{H}_{2} \mathrm{O}_{2}$ and the frequency of cloud processing. Concentrations of $\mathrm{H}_{2} \mathrm{O}_{2}$ are specified as a function of latitude and season using the photochemical model of Spivakovsky et al. [1990]. The frequency of cloud processing is estimated on the basis of GISS GCM data for cloud volume fractions in individual grid boxes [Chin et al., this issue].

Scavenging of $\mathrm{SO}_{2}$ and $\mathrm{SO}_{4}{ }^{2-}$ by precipitation is computed with the scheme described by Balkanski et al. [1993] and previously tested in the GISS GCM by simulation of ${ }^{210} \mathrm{~Pb}$ aerosol. The scheme accounts for efficient scavenging in the wet convective updrafts of the GCM as well as for rainout and washout from largescale precipitation. Wet scavenging of $\mathrm{SO}_{2}$ is contingent on rapid oxidation to $\mathrm{SO}_{4}{ }^{2-}$ and is therefore limited in polluted regions by the availability of $\mathrm{H}_{2} \mathrm{O}_{2}$. Dry deposition fluxes of $\mathrm{SO}_{2}$ and $\mathrm{SO}_{4}{ }^{2-}$ are computed with a resistance-in-series model [Wesely, 1989] as a function of surface type and meteorological conditions; the formulation accounts for seasonal changes in the deposition velocity due to snow and ice. The monthly mean $\mathrm{SO}_{2}$ dry deposition velocities in the model are $0.3-1.0 \mathrm{~cm} \mathrm{~s}^{-1}$ over ocean surfaces, $0.1-0.5 \mathrm{~cm} \mathrm{~s}^{-}$ ${ }^{1}$ over land, and $\sim 0.1 \mathrm{~cm} \mathrm{~s}^{-1}$ over desert and snow; the dry deposition velocity of $\mathrm{SO}_{4}{ }^{2-}$ ranges from 0.01 to $0.4 \mathrm{~cm} \mathrm{~s}^{-1}$ depending on surface roughness.

Chin et al. [this issue] present a detailed evaluation of model results with observations for $\mathrm{SO}_{4}{ }^{2-}$ and its precursors. The model reproduces typically to with $30 \%$ the observed $\mathrm{SO}_{2}$ and $\mathrm{SO}_{4}{ }^{2-}$ concentrations and $\mathrm{SO}_{4}{ }^{2-}$ wet deposition fluxes measured over the United States and Europe. Agreement to within $50 \%$ is found between model and observations for $\mathrm{DMS}, \mathrm{SO}_{2}$, and $\mathrm{SO}_{4}{ }^{2-}$ at surface sites in the southern hemisphere, with some exceptions. Model results for DMS, $\mathrm{SO}_{2}$ and $\mathrm{SO}_{4}{ }^{2-}$ in the free troposphere are generally consistent with the few observations available. The model underestimates the observed $\mathrm{SO}_{4}{ }^{2-}$ concentrations over the North Pacific and the North Atlantic, partly because of precipitation anomalies in the GCM; better simulation is achieved in these regions for the $\mathrm{MSA} / \mathrm{SO}_{4}{ }^{2-}$ concentration ratio, which reflects the relative contributions of biogenic and anthropogenic sources to $\mathrm{SO}_{4}{ }^{2-}$ [Savoie and Prospero, 1989]. The observed transport of sulfate from Eurasia to the Arctic in winter and spring is reproduced in the model for the European Arctic but is underestimated for the North American Arctic.

All results presented below are from the standard model simulation described above, and from sensitivity simulations where emissions from specific sources have been reduced or removed. All the simulations are conducted for the same period of 15 months, starting from low initial conditions. Only the last 12 months are used for analyses.

\section{Export of Anthropogenic Sulfur From Polluted Continents}

Figure 1 shows the horizontal and vertical fluxes of total sulfur between $10^{\circ} \mathrm{N}$ and $70^{\circ} \mathrm{N}$ in summer (June - August) and winter (December - February) in the standard model, for the lower tropospheric column extending from the surface to $2.6 \mathrm{~km}$ (top of model layer 3 ). This column is taken to represent the continental boundary layer in the model [Jacob et al., 1993]. The United States, Europe, and eastern Asia (as defined in Figure 1) account together for $70 \%$ of total anthropogenic sulfur emissions in the GEIA data base for 1985 [Benkovitz et al., 1996].

Sulfur budgets for the U.S. boundary layer in summer and winter are given in Figure 2. Over $95 \%$ of the $\mathrm{SO}_{2}$ source in the region is anthropogenic. About $80 \%$ of $\mathrm{SO}_{2}$ is lost within the region by deposition and oxidation, both in summer and winter; dry deposi- 

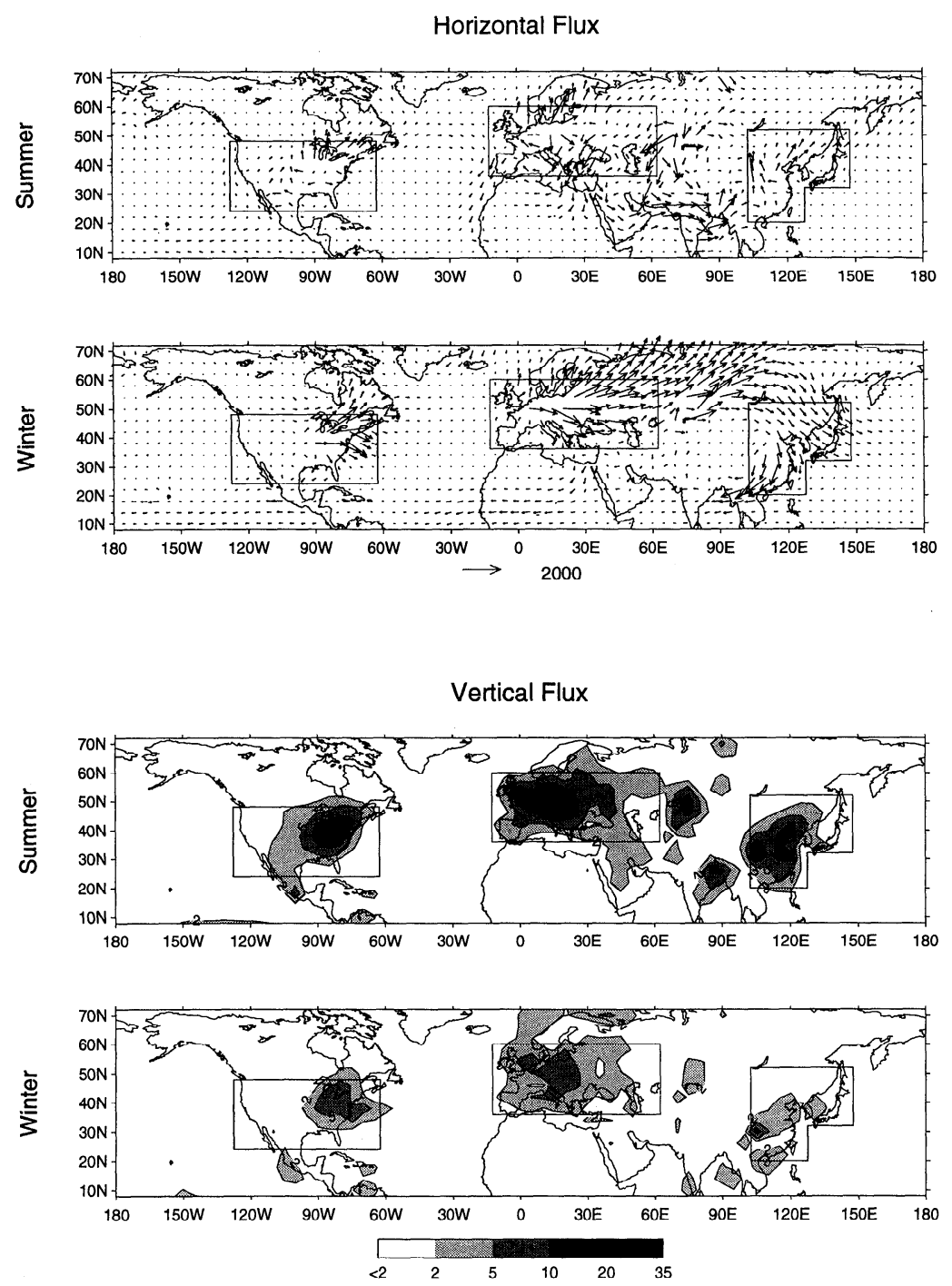

Figure 1. Seasonally averaged horizontal and upward vertical fluxes of total sulfur $\left(\mathrm{mg} \mathrm{S} \mathrm{m}^{-2} \mathrm{~d}^{-1}\right)$ between $10^{\circ} \mathrm{N}$ and $70^{\circ} \mathrm{N}$ for the $0-2.6 \mathrm{~km}$ column in summer (June - August) and winter (December - February). The boxed regions are referred to in the text as the United States, Europe, and eastern Asia. Surface areas for these regions are: United States, $1.43 \times 10^{13} \mathrm{~m}^{2}$; Europe, $1.79 \times 10^{13} \mathrm{~m}^{2}$; eastern Asia, $1.16 \times 10^{13} \mathrm{~m}^{2}$.

tion and aqueous-phase oxidation in clouds account together for $70 \%$ of $\mathrm{SO}_{2}$ loss in both seasons. The dry deposition velocity of $\mathrm{SO}_{2}$ is less in winter than in summer because of snow cover and weaker turbulence, and the supply of $\mathrm{H}_{2} \mathrm{O}_{2}$ for aqueous-phase oxidation of $\mathrm{SO}_{2}$ is also less in winter. Thus the lifetime of $\mathrm{SO}_{2}$ against deposition and oxidation within the region is 0.6 days in summer and 1.3 days in winter. This seasonal difference in $\mathrm{SO}_{2}$ lifetime translates into a factor of 2 increase of $\mathrm{SO}_{2}$ concentrations between summer and winter.

Despite the longer lifetime of $\mathrm{SO}_{2}$ in winter, we find that the fraction of $\mathrm{SO}_{2}$ exported out of the U.S. boundary layer $(21 \%)$ is only marginally higher than in summer $(17 \%)$ because of less active convection. In summer, $90 \%$ of $\mathrm{SO}_{2}$ export in the model is by ventilation to the free troposphere, principally over the eastern United States where the emissions are concentrated. In winter, by contrast, convection is infrequent and transport to the free troposphere accounts for only $30 \%$ of export; lower troposphere advection to eastern Canada and the North Atlantic is dominant.

About $40 \%$ of the $\mathrm{SO}_{2}$ emitted in the United States is oxidized to $\mathrm{SO}_{4}{ }^{2-}$ within the U.S. boundary layer. This $\mathrm{SO}_{4}{ }^{2-}$ is removed from the boundary layer by wet and dry deposition with a mean lifetime of 6 days in summer and 2 days in winter. Rodhe and Grandell [1972] estimated that the $\mathrm{SO}_{4}{ }^{2-}$ lifetime against precipitation in Sweden is 4-12 days in summer and 1.5-3 days in winter; our results for the United States are comparable. The frequency of precipitation is the principal variable determining the lifetime of soluble tracers against wet deposition [Rodhe and Grandell, 1972; Giorgi and Chameides, 1986]. Because most of the sulfate is produced in cloud, we may expect the lifetime of $\mathrm{SO}_{4}{ }^{2-}$ against precipitation to be shorter than would be defined simply from the precipitation frequency. The shorter lifetime of $\mathrm{SO}_{4}{ }^{2-}$ in winter than in summer reflects a seasonal difference in the nature of precipitation; summertime precipitation, which is mainly convective, is more intense but less frequent than wintertime precipitation, which is primarily synoptic. We find in the model that only $30 \%$ of $\mathrm{SO}_{4}{ }^{2-}$ produced over the United States in winter is exported, as compared to $70 \%$ in summer, because of the rapid deposition in winter.

Model results thus indicate that the fraction of anthropogenic sulfur exported out of the U.S. boundary layer ranges from $35 \%$ in 

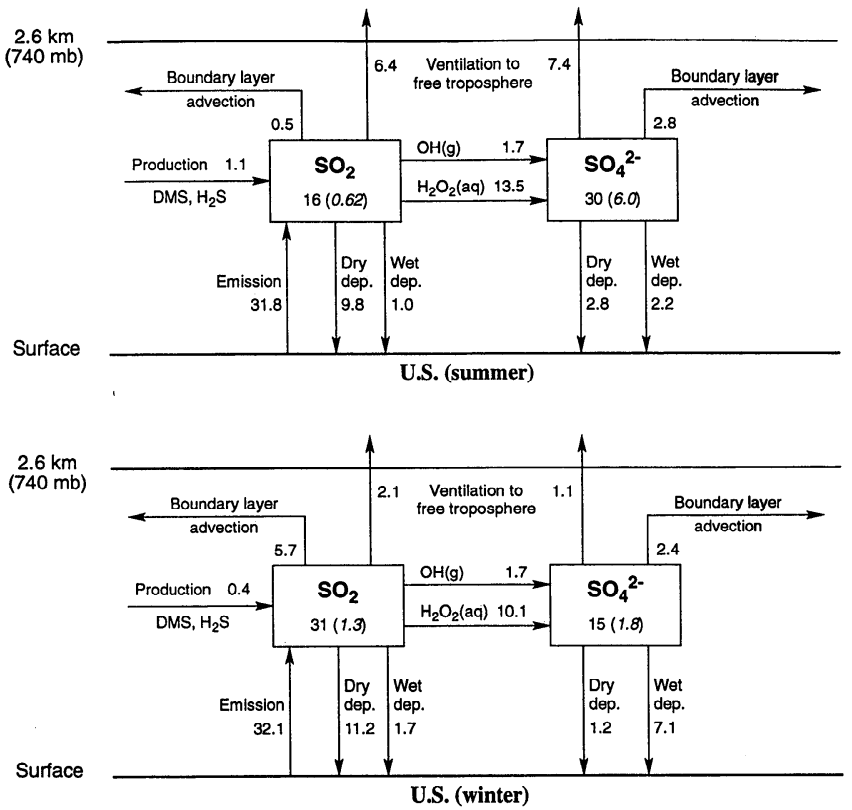

Figure 2. Regional budgets of $\mathrm{SO}_{2}$ and $\mathrm{SO}_{4}{ }^{2-}$ simulated by the model for the 0-2.6 km atmospheric column over the United States in summer (June - August) and winter (December - February): inventories $(\mathrm{Gg} \mathrm{S})$, fluxes $\left(\mathrm{Gg} \mathrm{S} \mathrm{d}^{-1}\right)$, and lifetimes (days, in parentheses). The horizontal extent of the U.S. region is shown in Figure 1. The lifetime of $\mathrm{SO}_{2}$ is defined with respect to losses from oxidation and deposition. The lifetime of $\mathrm{SO}_{4}{ }^{2-}$ is defined with respect to loss from deposition.

winter to $50 \%$ in summer. Export in winter is mostly as $\mathrm{SO}_{2}$ (70\%), while in summer it is mostly as $\mathrm{SO}_{4}{ }^{2-}(60 \%)$. Galloway et al. [1984] previously estimated that $34 \%$ of the sulfur emilted in eastern North America is exported to the North Atlantic in the 0$5.5 \mathrm{~km}$ column between $25^{\circ} \mathrm{N}$ and $60^{\circ} \mathrm{N}$ on an annual basis, $40 \%$ as $\mathrm{SO}_{2}$ and $60 \%$ as $\mathrm{SO}_{4}{ }^{2-}$. This estimate was made on the basis of measured atmospheric columns of $\mathrm{SO}_{2}$ and $\mathrm{SO}_{4}{ }^{2-}$ over the eastern United States combined with climatological mean winds for the east coast of North America. The seasonal variation of export was not discussed. Our sulfur budget for the United States is not inconsistent with that of Galloway et al. [1984] to the extent that the two are comparable.

Annual mean boundary layer budgets of $\mathrm{SO}_{2}$ and $\mathrm{SO}_{4}{ }^{2-}$ computed in the model for the United States, Europe, and eastern Asia are shown in Figure 3. All three regions are remarkably similar in the relative contributions of individual processes to the regional sulfur budgets. Net export of sulfur amounts to about $40 \%$ of the $\mathrm{SO}_{2}$ source for each region. There is significant import of sulfur into eastern Asia in winter from industrial sources in Kazakhstan (Figure 1). The $\mathrm{SO}_{2} / \mathrm{SO}_{4}{ }^{2-}$ ratio of the exported sulfur is highest in Europe because of the relatively high latitudes and hence slow $\mathrm{SO}_{2}$ oxidation rates.

Changes in sulfur emissions in the above regions affect the regional sulfur budgets nonlinearly because of the limitation of incloud $\mathrm{SO}_{2}$ oxidation by the availability of $\mathrm{H}_{2} \mathrm{O}_{2}$. To examine the extent of this effect, we conducted a sensitivity simulation with anthropogenic $\mathrm{SO}_{2}$ emissions decreased uniformly by $50 \%$ from the standard simulation. Table 1 shows the percentage values of the individual budget terms relative to the standard simulation for the U.S. boundary layer. The concentrations of $\mathrm{SO}_{2}$ are $42-45 \%$ of their values in the standard simulation, i.e., a more-than-linear decrease, because of the greater relative availability of $\mathrm{H}_{2} \mathrm{O}_{2}$ for incloud oxidation. The concentrations of $\mathrm{SO}_{4}{ }^{2-}$ show, by contrast, a less-than-linear decrease. The sulfur wet deposition flux (including scavenging of both $\mathrm{SO}_{4}{ }^{2-}$ and $\mathrm{SO}_{2}$ ) is $66 \%$ in winter and $59 \%$ in summer of the values in the standard simulation; this nonlinearity is similar to that previously obtained by Misra et al. [1989] in a regional model simulation for eastern North America. The export of sulfur from the U.S. boundary layer in winter is $44 \%$ of the value in the standard simulation, a more-than-linear decrease, because the lifetime of $\mathrm{SO}_{4}{ }^{2-}$ against deposition in winter is less than that of $\mathrm{SO}_{2}$. Negligible nonlinearity is found for the export of sulfur in summer because the nonlinear effects on $\mathrm{SO}_{2}$ and $\mathrm{SO}_{4}{ }^{2-}$ deposition nearly cancel. On an annually averaged basis, the export of sulfur from the U.S. boundary layer responds almost linearly to a decrease in anthropogenic emission, but the $\mathrm{SO}_{2} / \mathrm{SO}_{4}{ }^{2-}$ ratio of the exported sulfur decreases as the emission decreases. Similar results are found for Europe and for castern Asia.

\section{Origin of Sulfate in the Global Atmosphere}

Figure 4a shows the annual mean $\mathrm{SO}_{4}{ }^{2-}$ concentrations from the standard simulation in surface air (lowest model layer, 0-500 m above the surface), the middle troposphere (650 mbar), and the
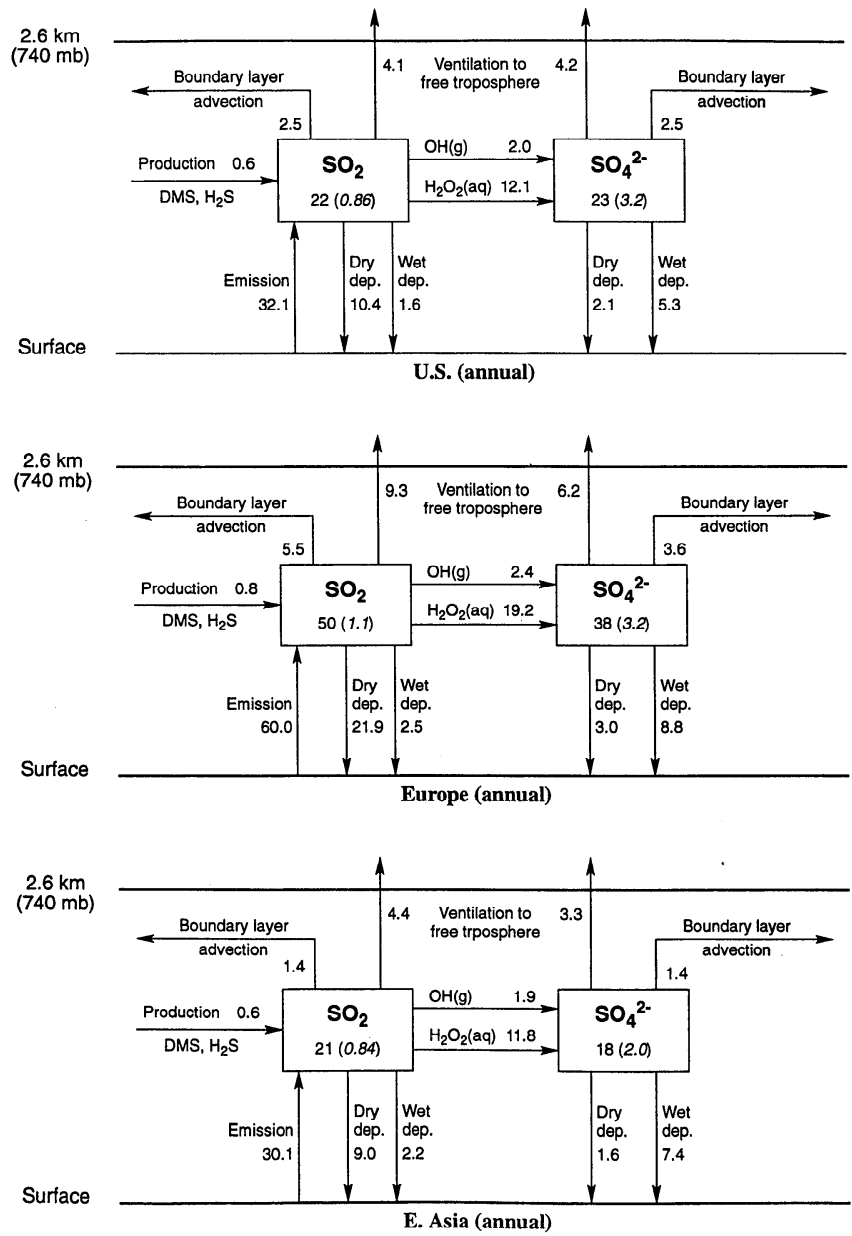

Figure 3. Annual mean regional budgets of $\mathrm{SO}_{2}$ and $\mathrm{SO}_{4}{ }^{2-}$ simulated by the model for the $0-2.6 \mathrm{~km}$ columns over the United States, Europe, and eastern Asia: inventories ( $\mathrm{Gg} \mathrm{S})$, fluxes ( $\mathrm{Gg} \mathrm{S}$ $\mathrm{d}^{-1}$ ), and lifetimes for $\mathrm{SO}_{2}$ and $\mathrm{SO}_{4}{ }^{2-}$ (days, in parentheses). The horizontal extent of each region is shown in Figure 1. See caption to Figure 2 for definition of lifetimes. 
Table 1. Effect of Reducing Sulfur Emisions in the United States by $50 \%$

\begin{tabular}{lccc}
\hline & Summcr, \% & Winter, \% & Annual, \% \\
\hline Anthropogenic $\mathrm{SO}_{2}$ emission & 50 & 50 & 50 \\
$\mathrm{SO}_{2}$ burden & 45 & 42 & 44 \\
$\mathrm{SO}_{4}{ }^{2-}$ burden & 60 & 66 & 61 \\
$\mathrm{SO}_{2}$ gas-phase oxidation & 46 & 44 & 44 \\
$\mathrm{SO}_{2}$ in-cloud oxidation & 60 & 66 & 62 \\
Total sulfur dry deposition & 50 & 47 & 48 \\
Total sulfur wet deposition & 59 & 66 & 63 \\
Total sulfur deposition (dry+wet) & 51 & 55 & 53 \\
Total sulfur export & 51 & 44 & 48 \\
\hline
\end{tabular}

The table shows the percentage values of the individual sulfur budget terms for the U.S. boundary layer (see text for definition), in a simulation where anthropogenic sulfur emissions were decreased by $50 \%$ relative to the standard simulation. Values lower than $50 \%$ indicate a more-thanlinear effect of cmission reduction; values higher than $50 \%$ indicate a lessthan-linear effect.

upper troposphere (330 mbar). The relative contributions of anthropogenic, biogenic, and volcanic sources to these $\mathrm{SO}_{4}{ }^{2-}$ concentrations are shown in Figure $4 \mathrm{~b}$. The small biomass burning source is treated here as anthropogenic. We find that anthropogenic sources account for more than $90 \%$ of total $\mathrm{SO}_{4}{ }^{2-}$ in surface air over North America and Eurasia, and also over polluted continental regions of the southern hemisphere: South America (copper smelters in Peru and Chile, coal in Brazil), southern Africa (copper smelters, biomass burning), and eastern Australia (coal). Sulfatc in Arctic surface air is also dominantly anthropogenic on an annually averaged basis, reflecting the strong influx of Eurasian pollution in winter-spring [Barrie and Hoff, 1984]. During summer, however, $\mathrm{SO}_{4}{ }^{2-}$ concentrations in the Arctic are low and primarily of biogenic origin, both in the observations [Nriagu et al., 1991] and in the model [Chin et al., this issue].

As seen in Figure 4h, anthropogenic influence on $\mathrm{SO}_{4}{ }^{2-}$ in surface air decreases rapidly downwind of the polluted continents. The model may exaggerate this decrease, as it does not capture the seasonal anthropogenic enhancements of $\mathrm{SO}_{4}{ }^{2-}$ observed at island sites in the North Pacific and the North Atlantic [Chin et al., this issue]. It is found in the model that oxidation of biogenic DMS accounts for $20-80 \%$ of $\mathrm{SO}_{4}{ }^{2-}$ in surface air over the northern hemisphere oceans. Volcanoes make a significant contribution to $\mathrm{SO}_{4}{ }^{2-}$ in surface air over the North Pacific, reflecting long-range transport from continuous noneruptive emissions in Hawaii, the Pacific Rim, and central America. Anthropogenic influence on $\mathrm{SO}_{4}{ }^{2-}$ over the southern hemisphere oceans is largely restricted to the tropical Atlantic, where polluted air masses from southern Africa and Brazil converge [Krishnamurti et al., 1993]. Over most of the southern hemisphere, oxidation of biogenic DMS accounts for more than $80 \%$ of $\mathrm{SO}_{4}{ }^{2-}$ in surface air.

Figure $4 \mathrm{~b}$ also indicates that the anthropogenic influence on $\mathrm{SO}_{4}{ }^{2-}$ decreases rapidly with altitude. At $650 \mathrm{mbar}$, human activity still accounts for more than $50 \%$ of $\mathrm{SO}_{4}{ }^{2-}$ over most of the United States, Eurasia, and the high northern latitudes. At 330 mbar, however, human influence is less than $20 \%$ on average anywhere around the globe. Most of the transport of air from the surface to the upper troposphere takes place in wet convective updrafts, where $\mathrm{SO}_{2}$ and $\mathrm{SO}_{4}{ }^{2-}$ are efficiently scavenged by precipitation. The efficient scavenging of $\mathrm{SO}_{2}$ and $\mathrm{SO}_{4}{ }^{2-}$ in deep convective updrafts, as formulated in the model, appears necessary to match observed concentrations of $\mathrm{SO}_{4}{ }^{2-}$ in the upper troposphere [Chin et al., this issue]. Previous studies support the view that scavenging of soluble aerosols in deep convection is close to $100 \%$ [ Gatz, 1977; Balkanski et al., 1993]. Although wet convective pumping of $\mathrm{SO}_{2}$ in polluted air without scavenging might be expected in winter when the scavenging efficiency of $\mathrm{SO}_{2}$ is low (due to low levels of $\mathrm{H}_{2} \mathrm{O}_{2}$ ), the frequency of deep convection is also low during that time of year.

The relative importance of biogenic versus anthropogenic contributions to $\mathrm{SO}_{4}{ }^{2-}$ increases with altitude, reflecting the injection of DMS to high altitudes in convective updrafts. In contrast to $\mathrm{SO}_{2}$ and $\mathrm{SO}_{4}{ }^{2-}$, DMS is not scavenged during precipitation. Convective pumping of DMS thus represents a major source of $\mathrm{SO}_{4}{ }^{2-}$ to the upper troposphere in the model, as previously suggested by Chatfield and Crutzen [1984]. This mechanism is most efficient in the tropics where convective activity is most frequent. We find in Figure $4 \mathrm{~b}$ that the biogenic source accounts for over $80 \%$ of $\mathrm{SO}_{4}{ }^{2-}$ in the upper troposphere throughout the tropics except in regions of large volcanic eruptions.

Volcanoes are important contributors to the $\mathrm{SO}_{4}{ }^{2-}$ budget in the middle and upper troposphere, as shown in Figure $4 \mathrm{~b}$. The total volcanic source used in the model for 1985 is $6.7 \mathrm{Tg} \mathrm{S} \mathrm{yr}^{-1}$, slightly less than the 9-year mean value of $7.8 \mathrm{Tg} \mathrm{S} \mathrm{yr}^{-1}$ for 1964-1972 cstimated by Spiro et al. [1992]. Volcanic activity in 1985 was somewhat weaker than average [Simkin and Siebert, 1994]; there were in particular no eruptions with volcanic explosivity index (VEI) higher than 3 which would inject sulfur into the stratosphere. Six eruptions in 1985 had a VEI of 3, producing in the model eruption plumes extending to $9 \mathrm{~km}$ altitude: two in New Guinea, one in Indonesia, two in Kamchatka, and one in Colombia (Ruiz). The plumes from these eruptions are manifest at 330 mbar in Figure $4 \mathrm{~b}$. The relative contribution of eruptive volcanoes to the $\mathrm{SO}_{4}{ }^{2-}$ budget
Surface

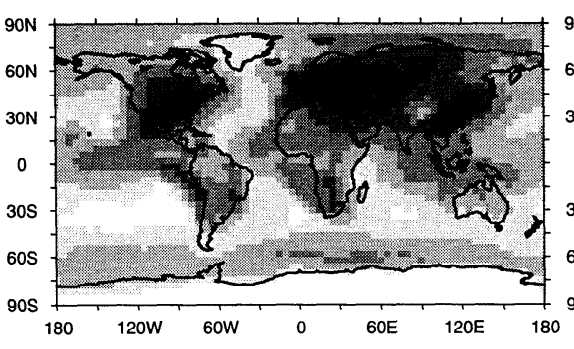

$650 \mathrm{mb}$

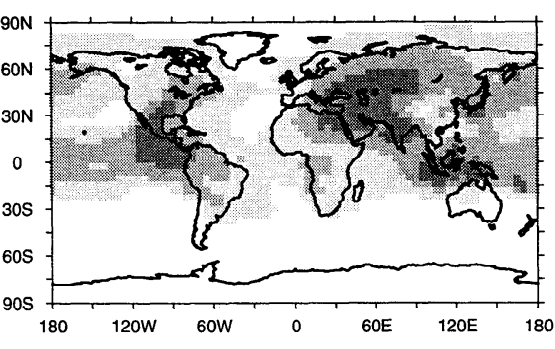

$330 \mathrm{mb}$

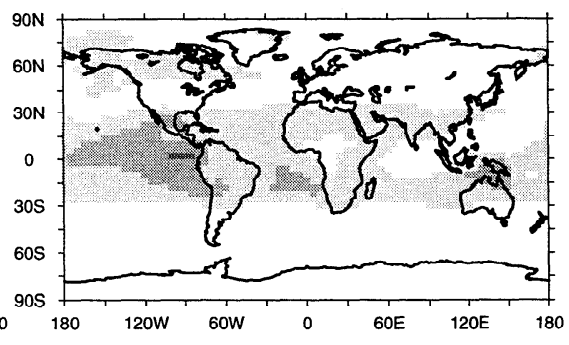

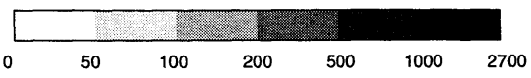

Figure 4a. Annual mean $\mathrm{SO}_{4}{ }^{2-}$ concentrations (ppt) in surface air $(0-500 \mathrm{~m})$, at $650 \mathrm{mbar}$, and at $330 \mathrm{mbar}$. 

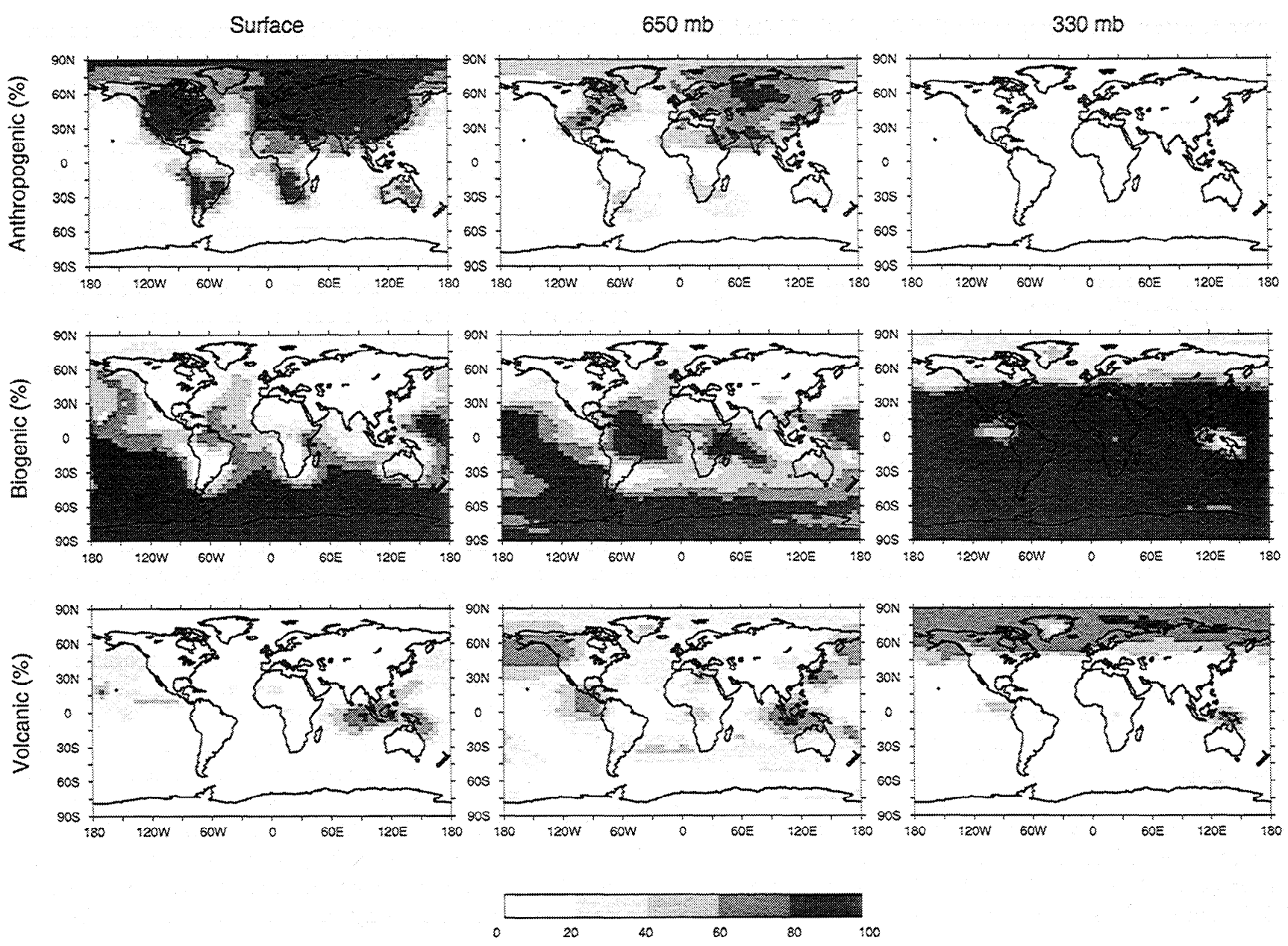

Figure 4b. Relative contributions (percents) of anthropogenic, biogenic, and volcanic sources to the annual mean $\mathrm{SO}_{4}{ }^{2-}$ concentrations simulated by the model in surface air $(0-500 \mathrm{~m})$, at $650 \mathrm{mbar}$, and at $330 \mathrm{mbar}$. Anthropogenic $\mathrm{SO}_{4}^{2-}$ concentrations are obtained from the difference between the standard simulation and a simulation without anthropogenic emissions. Biogenic $\mathrm{SO}_{4}{ }^{2-}$ concentrations are from a simulation with biogenic sources only (oceans and terrestrial). Volcanic $\mathrm{SO}_{4}{ }^{2-}$ concentrations are obtained from the difference between the simulation without anthropogenic emissions and the simulation with biogenic sources only.

in the upper troposphere is highest at high latitudes, where the supply of DMS by deep convection is wcak.

The large eruptions with VEI of 3 account together for only 1.2 $\mathrm{Tg} \mathrm{S} \mathrm{yr}^{-1}$ in our inventory for 1985 , i.e., $18 \%$ of the total volcanic source. The remaining source emanates from a large number of noneruptive and weakly eruptive volcanoes, discharging $\mathrm{SO}_{2}$ at the mouth of the crater (typically in the middle troposphere) or a few kilometers above, often continuously over the year. We find that this diffuse volcanic source accounts for $20-40 \%$ of $\mathrm{SO}_{4}{ }^{2-}$ over much of the middle troposphere at 650 mbar; in the North Pacific this contribution rises to $60-80 \%$, due primarily to the intense volcanic activity in Kamchatka.

The global mean vertical distribution of $\mathrm{SO}_{4}{ }^{2-}$ production from anthropogenic, biogenic, and volcanic sources in the model is summarized in Figure 5. Most of the $\mathrm{SO}_{4}{ }^{2-}$ in the lower troposphere is produced from anthropogenic sources, but biogenic and volcanic sources dominate at higher altitudes. The previous model simulation of Balkanski et al. [1993] showed that the lifetime of aerosols produced in the upper troposphere ( 17 days) is 4 times longer than that of aerosols produced in the boundary layer ( 4.4 days) because of less frequent scavenging by precipitation at high altitude. There results a strong disproportionality between the relative magnitudes of the $\mathrm{SO}_{4}{ }^{2-}$ sources and their contributions to the global atmospheric burden of $\mathrm{SO}_{4}{ }^{2-}$ (Table 2). Although human activity represents nearly $70 \%$ of the global sulfur source, it accounts for only $37 \%$ of the global $\mathrm{SO}_{4}{ }^{2-}$ burden in the model. Biogenic emissions account for $42 \%$ of the global $\mathrm{SO}_{4}{ }^{2-}$ burden although for only $23 \%$ of the source. Volcanic emissions account for only $7 \%$ of the global sulfur source but for $18 \%$ of the $\mathrm{SO}_{4}{ }^{2-}$ burden.

Comparing results from the simulations with and without anthropogenic sulfur emissions, we find that the anthropogenic enhancement of the $\mathrm{SO}_{4}{ }^{2-}$ burden is a factor of 1.6 globally (2.0 in the northern hemisphere and 1.2 in the southern hemisphere). Langner et al. [1992] previously estimated in the MOGUNTIA model that human activity had increased the global $\mathrm{SO}_{4}{ }^{2-}$ burden by a factor of 2.8 in the northern hemisphere and 1.4 in the southern hemisphere since preindustrial time, and Pham et al. [1996] found an even more pronounced increase in the northern hemisphere (a factor of 4) using the IMAGES model. These discrepancies between models may reflect differences in the efficiency of transport of anthropogenic sulfur to the free troposphere, as discussed by Chin et al. [this issue]. Convective transport of anthropogenic sulfur is greatly restricted in our model due to efficient scavenging of $\mathrm{SO}_{2}$ and $\mathrm{SO}_{4}{ }^{2-}$ in wet convective updrafts. In contrast, Pham et 


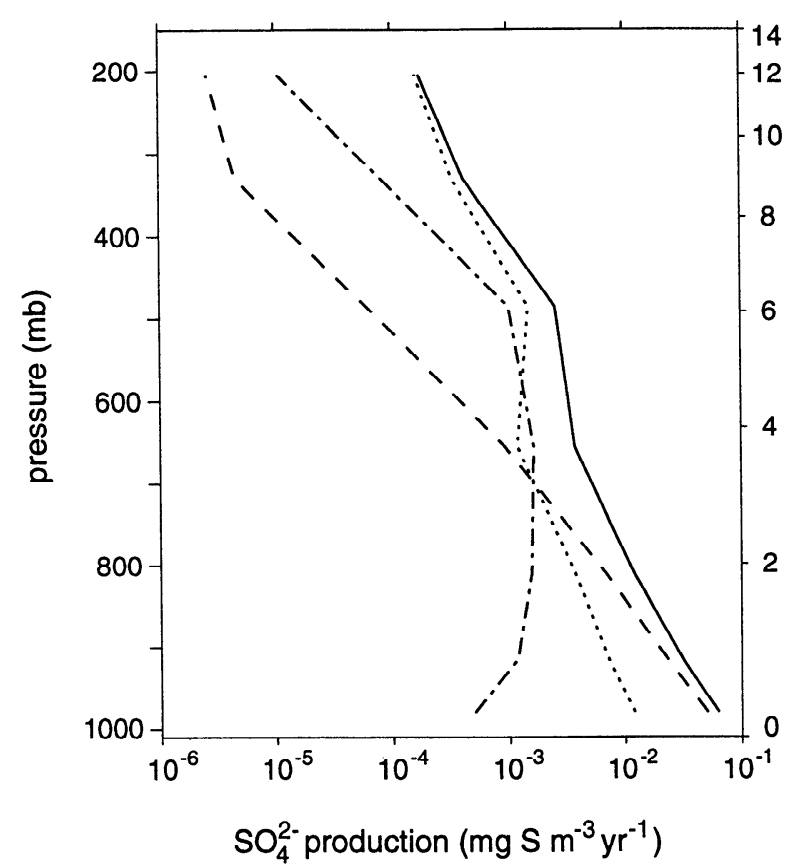

Figure 5. Annually averaged, global mean $\mathrm{SO}_{4}{ }^{2-}$ production rates (mg $S \mathrm{~m}^{-3} \mathrm{~d}^{-1}$ ) from all sources (solid line) and from anthropogenic (dashed line), biogenic (dotted line), and volcanic (dash-dot line) sources in the model as a function of altitude. The anthropogenic and volcanic sources are for 1985.

al. [1996] allowed anthropogenic sulfur to be injected to high altitudes in deep wet convection. As pointed out by Chin et al. [this issue] and earlier by Feichter et al. [1991] and Balkanski et al. [1993], the decoupling of convective mass transport and precipitation scavenging operators in a model can lead to overestimates of aerosol concentrations in the free troposphere.

Figure 6 shows the global distribution of the annual mean total $\mathrm{SO}_{4}{ }^{2-}$ column simulated by our model, along with the relative anthropogenic contribution to the column. We find that the anthropogenic contribution is $60-90 \%$ over the northern midlatitude continents, $20-40 \%$ over the extratropical oceans of the northern hemisphere, and less than $20 \%$ in the tropics and the southern hemisphere. Plots of the same quantity have been reported by Charlson et al. [1991], Penner et al. [1994], and Pham et al. [1996] for the MOGUNTIA, GRANTOUR, and IMAGES models, respectively. Charlson et al. [1991] found that the anthropogenic contribution to the atmospheric $\mathrm{SO}_{4}{ }^{2-}$ column was $70-90 \%$ over the northern midlatitude continents, greater than $50 \%$ over the extratropical oceans of the northern hemisphere, and less than $50 \%$

Table 2. Global Atmospheric Sulfur Source and $\mathrm{SO}_{4}{ }^{2-}$ Burden in the Model

\begin{tabular}{lcc}
\hline Global sulfur source, $\mathrm{Tg} \mathrm{S} \mathrm{yr}^{-1}$ & 96.7 & \\
Anthropogenic & 67.4 & $(70 \%)$ \\
Biogenic & 22.6 & $(23 \%)$ \\
Volcanic & 6.7 & $(7 \%)$ \\
& & \\
Global $\mathrm{SO}_{4}{ }^{2-}$ burden,Tg S & $0.53^{\mathrm{a}}$ & \\
Anthropogenic & 0.20 & $(37 \%)$ \\
Biogenic & 0.22 & $(42 \%)$ \\
Volcanic & 0.10 & $(18 \%)$ \\
\hline
\end{tabular}

${ }^{a}$ Oxidation of carbonyl sulfide accounts for $0.016 \mathrm{Tg} \mathrm{S}(3 \%)$ of the global $\mathrm{SO}_{4}{ }^{2-}$ burden, mainly in the stratosphere.
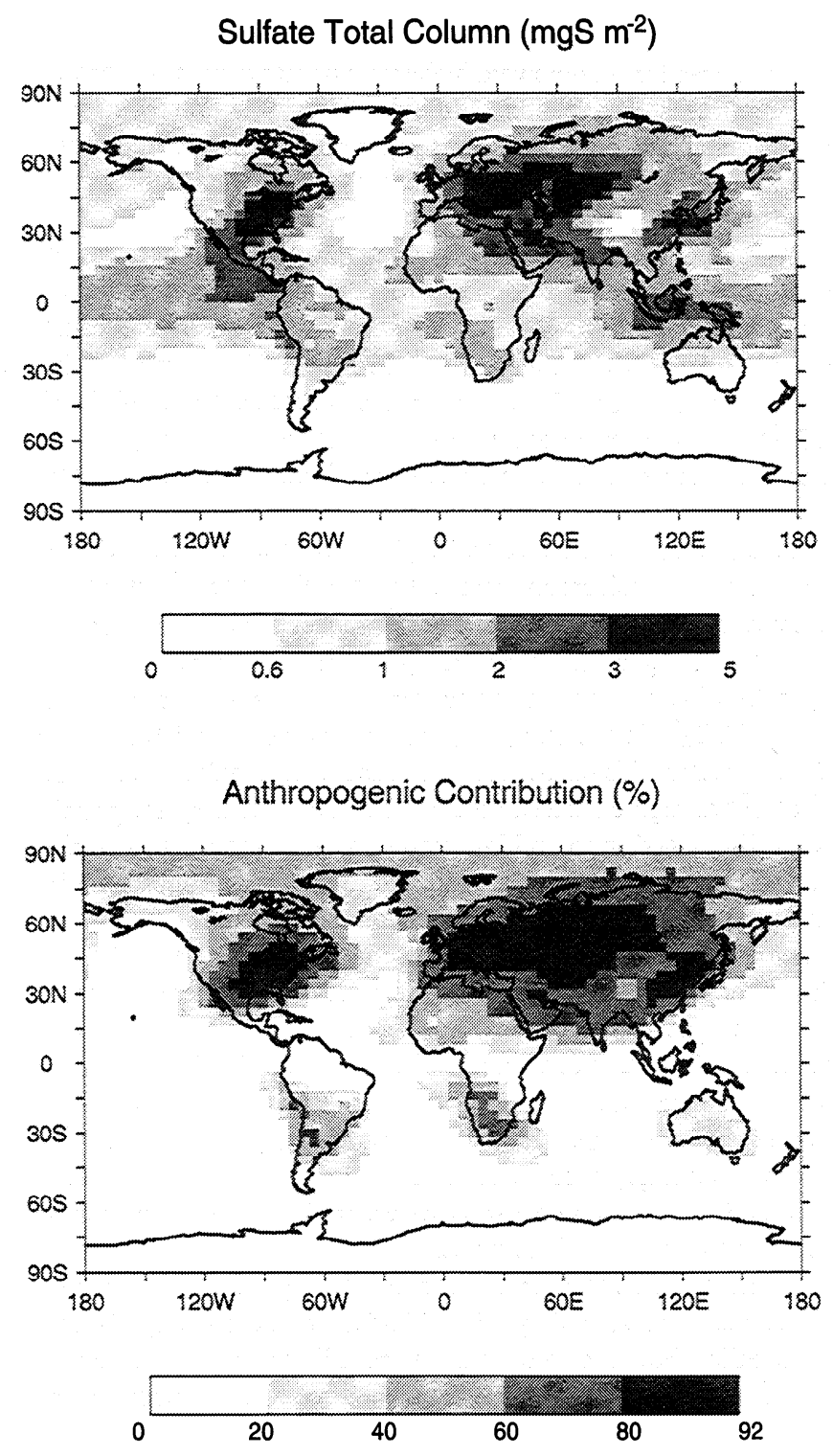

Figure 6. Global distribution of the annual mean atmospheric column of $\mathrm{SO}_{4}{ }^{2-}\left(\mathrm{mg} \mathrm{S} \mathrm{m}^{-2}\right)$ in the model, and relative anthropogenic contribution (percent) to this column.

in the tropics and the southern hemisphere. Similar results were found by Penner et al. [1994]. Pham et al. [1996] found an even higher anthropogenic contribution. Our total $\mathrm{SO}_{4}{ }^{2-}$ columns in the northern hemisphere are on average about $30 \%$ less than those of Charlson et al. [1991] and Penner et al. [1994], and 50\% less than those of Pham et al. [1996].

\section{Conclusions}

We have used a global three-dimensional model to analyze the export of anthropogenic sulfur out of polluted continents and to assess the relative contributions of anthropogenic and natural sources to $\mathrm{SO}_{4}{ }^{2-}$ levels in different regions of the troposphere. Examination of the sulfur budget in the three principal anthropogenic source regions (United States, Europe, eastern Asia) indicates that only about $40 \%$ of the $\mathrm{SO}_{2}$ emitted in these regions is exported from the continental boundary layer as $\mathrm{SO}_{2}$ or $\mathrm{SO}_{4}{ }^{2-}$, 
while the rest is removed by deposition within the region. The exported fraction is somewhat higher in summer than in winter due to more intense convection. Little nonlinearity is found between the magnitude of sulfur emissions in the northern midlatitude continents and the export of sulfur out of these continents to the global atmosphere.

Anthropogenic sources represent the main contributor to $\mathrm{SO}_{4}{ }^{2-}$ in surface air over most continental areas. Biogenic emission of DMS accounts for $20-80 \%$ of $\mathrm{SO}_{4}{ }^{2-}$ in surface air over oceanic areas in the northern hemisphere, and for over $80 \%$ in most of the southern hemisphere. Volcanic emissions account for $20-40 \%$ of $\mathrm{SO}_{4}{ }^{2-}$ in surface air over the North Pacific, reflecting major noneruptive sources in Kamchatka, Hawaii, Central America, and the Aleutians.

Anthropogenic influence on $\mathrm{SO}_{4}{ }^{2-}$ in the middle and upper troposphere is considerably less than at the surface because of efficient scavenging of $\mathrm{SO}_{2}$ and $\mathrm{SO}_{4}{ }^{2-}$ in wet convective updrafts. In contrast, biogenic DMS can be injected to high altitudes in cloud updrafts without experiencing scavenging. Thus we find that over $80 \%$ of $\mathrm{SO}_{4}{ }^{2-}$ in the tropical upper troposphere originates from DMS oxidation. Volcanoes are also found to be a major contributor to $\mathrm{SO}_{4}{ }^{2-}$ at high altitudes; volcanic emissions of $\mathrm{SO}_{2}$ are principally discharged in the middle troposphere, at the mouths of the volcanic craters, and some are injected to the upper troposphere in eruptions. We find that volcanoes account for $20-40 \%$ of $\mathrm{SO}_{4}{ }^{2-}$ in much of the middle troposphere, and dominate the $\mathrm{SO}_{4}{ }^{2-}$ budget in the upper troposphere at high northern latitudes. There has been much interest in the origin of $\mathrm{SO}_{4}{ }^{2-}$ in the upper troposphere because of its role in aerosol nucleation [Clarke, 1992], cirrus formation [Jensen and Toon, 1994] and tropospheric chemistry [Dentener and Crutzen, 1993]. Our results suggest that this $\mathrm{SO}_{4}{ }^{2-}$ is overwhelmingly natural; on an annual average basis, less than $20 \%$ of $\mathrm{SO}_{4}{ }^{2-}$ in the upper troposphere in the model is anthropogenic anywhere around the globe.

Because the atmospheric lifetimes of $\mathrm{SO}_{2}$ and $\mathrm{SO}_{4}{ }^{2-}$ against deposition increase rapidly with altitude, we find a strong disproportionality between the relative contributions of individual sources to global sulfur emission and their relative contributions to the $\mathrm{SO}_{4}{ }^{2-}$ atmospheric column. Thus anthropogenic sources in the model account for $70 \%$ of global sulfur emissions but for only $37 \%$ of the atmospheric $\mathrm{SO}_{4}{ }^{2-}$ column; biogenic emissions account for only $23 \%$ of the sulfur source but $42 \%$ of the column; while volcanic emissions contribute $7 \%$ of the source but $18 \%$ of the column. From a climate perspective, it appears that the contribution of anthropogenic sources to $\mathrm{SO}_{4}{ }^{2-}$ radiative forcing may be far less than one would estimate simply on the basis of their contribution to global sulfur emissions.

Acknowledgments. We thank Geraldine Gardner, Mike ForemanFowler, and Peter Spiro for their contributions to constructing the sulfur model. Comments from H. Rodhe, S. Schwartz, and an anonymous reviewer are gratefully acknowledged. This work was supported by the National Science Foundation (NSF-ATM-93-04217 and NSF-ATM-9320778), the National Aeronautics and Space Administration (NASANAGW-2632), and the Universities Space Research Association and NASA Goddard Space Flight Center (NAS5-32484).

\section{References}

Balkanski, Y. J., D. J. Jacob, G. M. Gardner, W. C. Graustein, and K. K. Turekian, Transport and residence times of tropospheric aerosols inferred from a global three-dimensional simulation of ${ }^{210} \mathrm{~Pb}, J$. Geophys. Res., 98, 20,573-20,586, 1993.

Barrie, L. A., and R. M. Hoff, The oxidation rate and residence time of sulphur dioxide in the arctic atmosphere, Atmos. Environ., 18, 2711-2722, 1984.
Barrie, L. A., M. P. Olson, and K. K. Oikawa, The flux of anthropogenic sulphur into the arctic from mid-latitudes in 1979/80, Atmos. Environ., 23, 2505-2512, 1989.

Benkovitz, C. M., M. T. Scholtz, J. Pacyna, L. Tarrason, J. Dignon, E. C. Voldner, P. A. Spiro, J. A. Logan, and T. E. Graedel, Global gridded inventories of anthropogenic emissions of sulfur and nitrogen, J. Geophys. Res., in press, 1996.

Charlson, R. J., J. Langner, H. Rodhe, C. B. Leovy, and S. G. Warren, Perturbation of the northern hemisphere radiative balance by backscattering from anthropogenic sulfate aerosols, Tellus, 43AB, 152$163,1991$.

Chatfield, R. B., and P. J. Crutzen, Sulfur dioxide in remote oceanic air: Cloud transport of reactive precursors, J. Geophys. Res., 89, 71117132, 1984.

Chin, M., and D. D. Davis, A reanalysis of carbonyl sulfide as a source of stratospheric background sulfur aerosol, J. Geophys. Res., 100, 8993$9005,1995$.

Chin, M., D. J. Jacob, G. M. Gardner, M. S. Foreman-Fowler, and P. A. Spiro, A global three-dimensional model of tropospheric sulfate, $I$. Geophys. Res., this issue.

Clarke, A. D., Atmospheric nuclei in the remote free-troposphere, I. Atmos. Chem., 14, 479-488, 1992.

Dentener, F. J., and P. J. Crutzen, Reaction of $\mathrm{N}_{2} \mathrm{O}_{5}$ on tropospheric aerosols: Impact on the global distributions of $\mathrm{NO}_{x}, \mathrm{O}_{3}$ and $\mathrm{OH}, J$. Geophys. Res., 98, 7149-7165, 1993.

Feichter, J., R. A. Brost, and M. Heimann, Three-dimensional modeling of the concentrations and deposition of ${ }^{210} \mathrm{~Pb}$ aerosols, J. Geophys. Res., 96, 22,447-22,460, 1991.

Galloway, J. N., D. M. Whelpdale, and G. T. Wolff, The flux of S and N eastward from North America, Atmos. Environ., 12, 2595-2607, 1984.

Gatz, D. F., A review of chemical tracer experiments on precipitation system, Atmos. Environ., 11, 945-973, 1977.

Giorgi, F., and W. L. Chameides, Rainout lifetimes of highly soluble aerosols and gases as inferred from simulations with a general circulation model, J. Geophys. Res., 91, 14,367-14,376, 1986.

Hansen, J., G. Russell, D. Rind, P. Stone, A. Lacis, S. Lebedeff, R. Ruedy, and L. Travis, Efficient three-dimensional global models for climate studies: Models I and II, Mon. Weather Rev., 111, 609-662, 1983.

Intergovernmental Panel on Climate Change, Climate Change 1994, Cambridge Univ. Press, New York, 1995.

Jacob, D. J., J. A. Logan, G. M. Gardner, R. M. Yevich, C. M. Spivakovsky, S. C. Wofsy, S. Sillman, and M. J. Prather, Factors regulating ozone over the United States and its export to the global atmosphere, J. Geophys. Res., 98, 14,817-14,826, 1993.

Jensen, E. J., and O.B. Toon, Ice nucleation in the upper troposphere: Sensitivity to aerosol number density, temperature, and cooling rate, Geophys. Res. Lett., 18, 2019-2022, 1994.

Krishnamurti, T. N., H. E. Fuelberg, M. C. Sinha, D. Oosterhof, E. L. Bensman, and V. B. Kumar, The meteorological environment of the tropospheric ozone maximum over the tropical south Atlantic, J. Geophys. Res., 98, 10,621-10,641, 1993.

Langner, J., J. Rodhe, P. J. Crutzen, and P. Zimmermann, Anthropogenic influence on the distribution of tropospheric sulphate aerosol, Nature, 359, 712-716, 1992.

Misra, P. K., R. Bloxam, C. Fung, and S. Wong, Nonlinear response of wet deposition to emissions reduction: A model study, Atmos. Environ., 23, 671-687, 1989.

Nriagu, J. O., R. D. Coker, and L. A. Barrie, Origin of sulphur in Canadian Arctic haze from isotope measurements, Nature, 349, 142-145, 1991.

Penner, J. E., C. A. Atherton, and T. Graedel, Global emissions and models of photochemically active compounds, in Proceedings, Ist International Global Atmospheric Biospheric Chemistry, edited by R. G. Prinn, pp. 223-248, Plenum, New York, 1994.

Pham, M., J.-F. Müller, G. Brasseur, C. Granier, and G. Megie, A 3D model study of the global sulfur cycle: Contributions of anthropogenic and biogenic sources, Atmos. Environ., in press, 1996.

Rodhe, H., and J. Grandell, On the removal time of aerosol particles from the atmosphere by precipitation scavenging, Tellus, 24, 442-454, 1972.

Savoie, D, L., and J. M. Prospero, Comparison of oceanic and continental sources of non-sca-salt sulphate over the Pacific Ocean, Nature, 339, $685-687,1989$.

Simkin, T., and L. Siebert, Volcanoes of the world: a regional directory, gazetteer, and chronology of volcanism during the last 10,000 years, Geoscience Press, 349 pp., Tucson, Arizona, 1994.

Spiro, P. A., D. J. Jacob, and J. A. Logan, Global inventory of sulfur emissions with $1^{\circ} \times 1^{\circ}$ resolution, J. Geophys. Res., 97, 6023-6036, 1992. 
Spivakovsky, C. M., R. Revich, J. A., Logan, S. C. Wofsy, M. B. McElroy, and M. J. Prather, Tropospheric $\mathrm{OH}$ in a three-dimensional chemical tracer model: and assessment based on observations of $\mathrm{CH}_{3} \mathrm{CCl}_{3}, J$. Geophys. Res., 95, 18,441-18,472, 1990.

Wesely, M. L., Parameterization of surface resistance to gaseous dry deposition in regional-scale numerical models, Atmos. Evniron., 23, 12931304, 1989.
M. Chin, USRA, NASA Goddard Space Flight Center, Code 916,

Greenbelt, MD 20771. (e-mail: chin@gatorl.gspc.nasa.gov)
D. J. Jacob, Division of Engineering and Applied Sciences and Department of Earh and Planetary Sciences, Harvard University, Cambridge, MA 02138. (e-mail: djj@io.harvard.edu)

(Received July 20, 1995; revised March 8, 1996; accepted April 9, 1996.) 